\title{
OCCUPATIONAL HEALTH \& SAFETY IMPLEMENTATION FRAMEWORK FOR PAKISTANI CONSTRUCTION INDUSTRY IN SINDH PROVINCE
}

Maryam Khokhar

School of Economics and Management

Yanshan, University, China.

E-mail: maryamkhokhar@stumail.ysu.edu.cn

Yumei Hou

School of Economics and Management

Yanshan, University, China.

E-mail: hym@ysu.edu
Inayatullah Sethar

School of Economics and Management

Yanshan, University, China.

E-mail: inayat90@stumail.ysu.edu.cn

Waqas Amin

School of Economics and Management

Yanshan, University, China.

E-mail: waqasamin@stumail.ysu.edu.cn

\section{Mohammad Shakib}

School of Economics and Management

Yanshan, University, China.

E-mail:shakibbd@gmail.com

Recepción: 02/08/2019 Aceptación: 24/09/2019 Publicación: 06/11/2019

\section{Gitación sugerida:}

Khokhar, M., Hou, Y., Inayatullah, Amin, W. y Shakib, M. (2019). Occupational Health \& Safety implementation framework for Pakistani construction industry in Sindh Province. 3C Tecnología. Glosas de innovación aplicadas a la pyme. Edición Especial, Noviembre 2019, 253285. doi: http://dx.doi.org/10.17993/3ctecno.2019.specialissue3.253-285

\section{Suggested citation:}

Maryam Khokhar, M., Hou, Y., Inayatullah, Amin, W. \& Shakib, M. (2019). Occupational Health \& Safety implementation framework for Pakistani construction industry in Sindh Province. 3C Tecnología. Glosas de innovación aplicadas a la pyme. Speciaal Issue, November 2019, 253-285. doi: http://dx.doi.org/10.17993/3ctecno.2019.specialissue3.253-285 


\section{ABSTRACT}

Construction companies' workers are facing higher injury rates as compared to other industries. The principal objective of this research is to investigate occupational health and safety $(\mathrm{OH} \& \mathrm{~S})$ training to be delivered effectively to the workers of the construction companies. The awareness level of employees' about OH\&S and how to facilitate the employees for OH\&S training to consequently have been studied. Both quantitative and qualitative method of study is implied collected by using construction self-administered questionnaire and face-to-face interviews. Statistical tools like frequency distribution and chi-square test has been used. Data obtained then examined by applying SPSS (Statistical Package for the Social Sciences) software. Three hundred respondents participated in the researcher's study to make the research valuable. It has been observed that levels of OH\&S knowledge vary from workers of various construction companies. It has also been investigated that varies how the construction workers been trained in $\mathrm{OH} \& \mathrm{~S}$.

\section{KEYWORDS}

Construction Company, Occupational health and safety (OH\&S), Construction workers, Survey, Pakistan. 


\section{INTRODUCTION}

Construction companies are treated as the backbone of any organization, playing a vigorous role in the economies of the country. This zone addresses immense people, and it deals with a varied range of audiences in terms of the workplace. The construction companies are like business access for the varietal change of people because governmental institutions, as well as private organizations, are stakeholders of these types of businesses and the boundaries of these companies are so broad that they ultimately get some difficulties along too. Construction industries are one of the most hazardous and risky among all industries (Imriyas, Pheng, \& Teo, 2007). Right at the beginning of these are concerns about OH\&S. Many analyses have confirmed that accidental occupational injuries and work-related diseases are under-compensated (Liao \& Chiang, 2015). According to them the workers must be educated in the OH\&S related concerns and on these issues several rules should be developed. Occupational coincidences not only scar employees' life and, loss the employers' human capital, but also increase the social cost of the country (Sámanoríos et al., 2019).

The majority of the workers in Pakistan are uneducated and not trained in the OH\&S. Moreover, $\mathrm{OH} \& \mathrm{~S}$ does not include in any curricula in Pakistan. The number of qualified workers in OH\&S is far less associated with the total labor force in Pakistan. It means that $\mathrm{OH} \& \mathrm{~S}$ training programs are not well-known in the country (Pasha, Liesivuori \& Finland, 2003). The arrival of the new Labor Policy 2002 (First after 1972), it was hoped that Pakistan would focus on the dignity of labor. The change in the existing labor legislation (as proposed in Labor Policy 2002) will help to solve the long-awaited questions. There is a great need for companies to surge the status of the OH\&S in Pakistan to compete in the international market and to encounter the developing tasks of globalization.

According to International Labour Organization (ILO) it was evaluated that at least 60,000 serious accidents happen annually on construction companies throughout the world (Cheng, Leu, Cheng, Wu, \& Lin, 2012) representing, one serious accident each and every 10 minutes and ILO also estimated that the total 
cost of work-related illness and injury are $4 \%$ of the gross national product of a given country (Shin, Oh, \& Yi, 2011)countries vary greatly with respect to how they organize workers' compensation systems. In this paper, we focus on three aspects of workers' compensation insurance in Organization for Economic Cooperation and Development (OECD . The construction companies are the most hazardous in the world because of fast industrialization and economic development. Inside the construction companies, the risk of a significant injury is 2.5 times higher, while the risk of fatality is five times higher than in manufacturing. There is a large number of unacceptable risks to all workers who are working in the variable nature of working conditions like dealing with construction projects, including workers, project managers, engineers, and so on (Zalk et al., 201 1; Bust, Gibb and Pink, 2008). Inside the construction companies, occupational injuries and fatalities have been related with important financial costs too. Estimated that such kind of hazardous injuries cost above 10 billion USD annually (Riaño-Casallas \& Tompa, 2018).

For approximating the cost of injuries and accidents, the worker's compensation is a vital origin (Friend \& Kohn, n.d.; Huang \& Hinze, 2006). It has been evaluated that the worker's compensation data from the United States were four times higher in direct the workers' compensation costs (medical treatment and indemnity) as compared to another company on average in construction companies (Marcum, Foley, Adams, \& Bonauto, 2018). In the construction companies, the fatal accident rate tends to be higher than that of other companies (Sørensen, Hasle, \& Bach, 2007). To reduce the ruins of occupational accidents, most of the countries have proposed laws for the prevention of occupational accidents and work-related injuries at the workplace. Predictably, these types of different means may have significant implications for system performance, including the employers and workers incentives to improve workplace safety and hence impact the actual occurrence rate of occupational injuries and diseases (Jain, Leka, \& Zwetsloot, 2018). Furthermore, Principles of $\mathrm{OH} \& \mathrm{~S}$ training of workers and ordinance provided that complete data about training has been issued. 
In the past few years, due to the focus on quality, time, cost, and the OH\&S issues are progressively being highlighted as a pointer for construction companies' success. For improving the construction sites providing the training to the workers as well as CCTV cameras would be helpful to recognize the approaching safety hazards in a sector (Seo, Han, Lee, \& Kim, 2015). Thibaut, Chi, Zhou, and Piramuthu, 2018 has recommended the wireless communication technology to overview the health and safety management related issues. In short, the mentioned experience intimates the desire or need to increase the training efficiency of workers who are working in construction companies. The specific training programs of workers improve the health and safety training of construction workers. These types of applications should be mainly concerned with accurate elucidations, unusually real time responsibilities. Training should be assembled on the model construction of the situation, approaches with reciprocal teaching methods, imaging techniques, containing databases and cataloged of frequently used solutions for the OH\&S.

The OH\&S has been measured as a main issue in the construction industry, especially in South Asian countries (Mohamed, Ali, \& Tam, 2009) where, OH\&S issues are significant anxiety because of the lack of Safety Acts (Zaid, Jaaron, \& Talib Bon, 2018). The lack of legislative regulations to keep construction workers, low standards in governance and corporate systems, high labor concentrated character and insufficient structure are other significant influences that combine to work in contradiction of safe conditions in south Asian countries, especially in Pakistan. Pakistan, a developing country, is presently facing a definite progress in construction activities. For this cause, the construction industry in Pakistan seriously funds to the gross domestic product and works about $8 \%$ of the total labor force (Zaid et al., 2018). Unfortunately, current general OH\&S rules do not directly apply to the industry. The lack of such a set of OH\&S rules poorly disturbs the implementation of a safe environment, thus resultant in more susceptible situations on the worker's performance. Current site examination facilities are not satisfactory enough to know or assess occupational injuries at the workplace. Accidents and injuries recording and reporting systems are dysfunctional. Both labors and administrators are not too 
worried about OH\&S since they are not educated about the statistics of injuries regarding different conditions.

\section{LITERATURE REVIEW}

During the last decades, there has been a growing awareness about OH\&S risk issues, and by administrative supervision in the construction industries. Moreover, despite the considerable developments succeeded, the rate of injuries is still significantly advanced than in other sectors (Sousa, Almeida, \& Dias, 2015). In the construction industry, the $\mathrm{OH} \& \mathrm{~S}$ has been measured as a significant issue, with construction actuality, one of the most hazardous industries. It is mainly so in south Asian countries (Coble \& Haupt, 1999; Ofori, 2000) where, the OH\&S is a central unease because of the lack of health and safety regarding Acts (Larcher \& Sohail, 1999). So many countries can play the leading role in the OH\&S training programs of the employees because OH\&S hazards are the universal content even though cultural differences. Therefore, the education-concentrated system, the working condition of the companies in various countries, the worker's profiles should be taken into notice. When talking about research studies related to OH\&S training in Pakistan, only few studies found in literature. Construction workers' approach to health and safety is subjective to awareness of safety at the workplace, guidelines and risk management issues regarding safety and health. South Asian counters are now facing a resilient development in its construction sides. Unluckily, the implementation of safety rules in Pakistan is not well-known. Definitely, some applicable principles are both outmoded and inappropriate to daily construction activities (Mohamed, Ali, \& Tam, 2009) Within a certain period of time, labor productivity is simply defined as the amount of work done by craft workers Kazaz and Acrkara (2015),Mahamid (2013) and Arditi and Mochtar (2000).

According to Jarullah, Abed, Ahmed, and Mujtaba (2019) both employers and employees lacked educational training of $\mathrm{OH} \& \mathrm{~S}$ rules/regulations, and no practices of this nature are passed at these construction operations. So, whenever work-related accidents happen, there are not given outstanding responsiveness and no official 
accident-report system. In the construction industries lack of OH\&S trainings occurs at an incredible human cost. Physical factors make joints and bonds less flexible and many lead young people to handle equipment more awkwardly, or their smaller size may place them at a higher risk of injury while handling operating instrument machines.

\subsection{CONSTRUCTION INDUSTRY IN PAKISTAN}

Health and Safety can be defined as the "ailment of being safe as of injury or damage, and consequently, live in a safe state. It is energetic that every participant/ worker/operative member of the civic is in a secure form, for both physical and mental well-being. Secure systems of labor tolerate compact opportunity of any worker, tools or organization being hurt or injured, and therefore decreasing the menaces of a worker losing incomes collected with improved construction budgets and intervals to a development. Hazardous work comprehends conditions such as individual abandon about messy work areas and non-reporting of possible health and safety issues. It is easy for contractors to change labors who are not performing well at a satisfactory level because of high unemployment rates. That's why employees commonly take risks which incline to raise the level of fatalities and accidents at the workplace. Employees will lean to hazardous accidents at the workplace because of their negligence and accept that working in construction sides is a hazardous occupation. Usually, regulations/ rules to defend employees are not severely imposed, and workers are not profoundly involved with economic advantage payments to incapacitated labors (Health, Safety \& Environment Aspects in Civil works, 2013).

These following general rules should be observed at the construction area like;

1) Only approved/authorized workers must check-in and checkout and they should report to site manager/security guard/supervisor

2) Under special conditions, visitors may visit and stay with authorized protectors during the project visit, and the escort must be familiar with the project site ultimately. 
3) All persons, including workers as well as visitors, must wear a hard cap, and the escort should make an availability of hard cape on construction sites.

4) All the workers should wear leader shoes while in the construction area.

5) Keep a safe distance from the construction site unless permitted by an authorized person.

6) Do not walk under the suspended material.

7) Obey all the signs and warnings marked as "no smoking" "warning" etc.

8) Waste dumping in the construction area is rigorously verboten.

9) Earplug must be worn while working on machinery.

10) Watch your every step and be aware of possible hazards.

11) All the time remain under the instruction of the emergency team supervisor at the time of an accident.

The construction sector has the highest injury accident rates in the workplace as compared to other industries result in extra avoidable labor-costs (Raheem \& Issa, 2016). All of these costs could be qualified to accepted complications of construction companies and the casual working environment at the workplace (Khan, Ali, De Felice, \& Petrillo, 2019)Occupational Health and Safety (OHS. This has through health and safety a significant subject for the construction operation, especially for south Asian countries because such countries are relatively meager at emerging and employing safety rules/regulations (Awwad, El Souki, \& Jabbour, 2016). Besides management, other issues such as low standards, inadequate infrastructure, and the labor force are the significant reasons of safety issues in these countries (Weissbrodt \& Giauque, 2017) and all of these issues mentioned above make the construction company one of the most dangerous companies (Mazlina Zaira \& Hadikusumo, 2017)the importance of safety intervention for changing unsafe to safe worker behaviour is known. For this reason, an integrated safety intervention model affecting workers' safety behaviour was developed and tested. This study was conducted by distributing a questionnaire 
survey to construction companies. The survey was randomly distributed, with a total of 198 responses received. Exploratory factor analysis (EFA.

Singh (1979) stated in their research that in the meanness of technical developments, construction side in south Asian countries, including Pakistan, sincerely trusts upon labor-intensive and conventional techniques of construction work. Such practices then give increase to $\mathrm{OH} \& \mathrm{~S}$ issues related to construction industry experts, end operators and the appropriate location is susceptible. South Asian countries' utmost need to investigate the situation, 'health and safety in Pakistan Construction Company' has acknowledged very less consideration from the academe and industrial researchers as well.

According to Hussain et al. (2013), working project executives at construction companies in Pakistan study the labor productivity of construction workers. Mohd Kamar, Lop, Mat Salleh, Mamter and Suhaimi (2014) have found out the awareness of the health and safety of construction workers. Injuries and accident rates in construction industries add to distract living values and manufacture financial and commercial difficulties for employees (By, Mushtaq, \& Khalid, 2015). Injuries are the leading cause of the global burden of disability and death for all working-age groups (WHO, 2012). As reported by the Australian industrial Commission (AIC), for every $\$ 1$ of the direct cost of injury estimates, $\$ 3$ to $\$ 5$ of indirect damages is also incurred (Bi et al., 2015). Globally Pakistan was ranked the 9th populated country in 2017, with the total labor force of 54.9 million (Government of Pakistan, 2018). Every year, an occupational injury/ incidences, 41 workers out of 1000 received an injury in the construction companies of Pakistan (Wu, Luo, Wang, Wang, \& Sapkota, 2018).

\subsection{OBJECT OF THE STUDY}

The main object of this research is to investigate the worker's awareness about in construction sites in Pakistan, to determine the way of training to be given, to analyze the reasons that caused occupational injury, possible injury rate by socio-economic, regional variables and find out OH\&S hazards. With similar companies' climate. These findings can potentially applicable with other developing countries or can be 
considered as prior research. The percent study aim is to understand the significance of $\mathrm{OH} \& \mathrm{~S}$ training to the construction workers in Pakistan construction industries. The present study will explore the effect of Socio-demographic characteristics of the workers who are working in Pakistan construction companies.

\section{METHODOLOGY}

Both quantitative and qualitative techniques were employed. The questionnaire tool as the quantitative method was used to determine the workers' profile and their knowledge OH\&S about containing 21 questions. The researcher studied previous literature and developed the questionnaire keenly. The survey was shown to experts and got their advice for the content of the review and its validity. Pilot testing was conducted to remove the possible faults in the survey so that organized and systematic results can be drawn efficiently. For this purpose, 28 workers were chosen to work on various construction sites. After testing the study, unnoticed spelling mistakes were removed, and some statements were made clear that were difficult to understand.

It is insured workers listed under the construction industry have been selected to determine the target population. A total of 284 respondents was selected with 5\% error margin and a $95 \%$ confidence level by utilizing the equilibrium provided in the following equation (Sanders, 1990).

$$
n=\frac{z 2 \mathcal{N} p q}{\mathcal{N} D 2+z 2 p q}
$$

In this survey, 300 participants have an essential role, and all of 300 reviews were analyzed by using statistical tools as the questionnaires were a little more than sampling numbers. This study is carried out 35 various big projects in Sindh especially, Karachi and Sukkar, as cities are considering the economic hub in Pakistan, especially in Sindh province. The respondents working on construction sites filled the questionnaire. The interviews were also organized at the workplace from November to December 2018. 
The obtained data of the worker's demographic knowledge, their level of education, and their concepts regarding OH\&S were analyzed by applying the SPSS. To find the frequency distribution of the data descriptive statistical tool was employed. For this purpose, pie charts and frequency tables have been used to unfolding the frequency distribution. To get comprehensive evidence of the data, the researcher analyzed the frequency and its distribution across the data. As well as chi-square test and cross-tabulations were also used to find out the relationship between the variables. The significant correlation between the variables is calculated by the chi-square test. The data were analyzed by the regulation/rule implemented in Pakistan. That's why, Dock Labourers Act 1934, Factories Act 1934, Mines Act 1923 is used to compare the action and obtained data.

\section{RESULTS AND DISCUSSIONS}

\subsection{FREQUENCY ANALYSIS}

The frequency analysis and distribution tools were used to obtain comprehensive evidence of the participating worker's data acquired from the survey. For that purpose, the answers related to sample study were obtained as frequency distributions and pie charts.

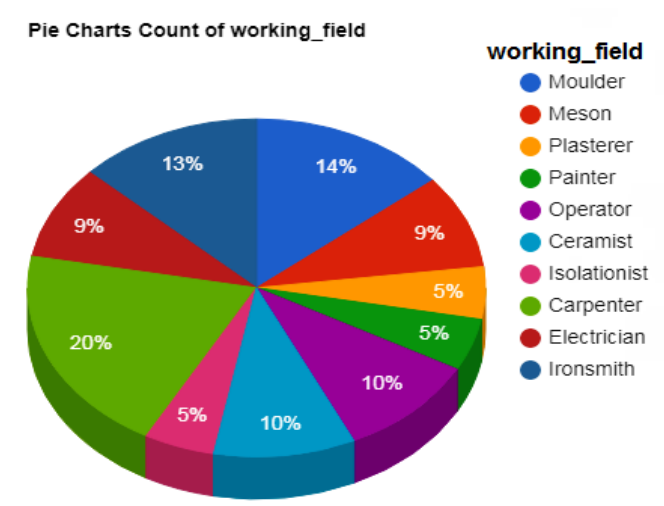

Figure 1. Division of workers' according to their work performed in the construction industry. 
Figure 1 described the worker's participation in the construction companies are distributed according to the base of their working field, respectively, the two fields acquired the highest percentage, the carpenter with $20.0 \%$, molder with $14.0 \%$ and ironsmith with $13.0 \%$. The field of study with a minimum percentage is a plasterer, painter and isolationist with $5.0 \%$ and the electrician with $9.0 \%$. It was observed that the high percentage of the workers were to be working in the comfortable zone.

Figure 3 illustrated the working period of workers in the workplace. Based on data, $12.0 \%$ of employees have less than a year working experience, $35.0 \% 1-10$ years, $29.7 \% 11-20$ years, $18.0 \%$ 21-30 years and $5.3 \%$ work for more than 30 years.

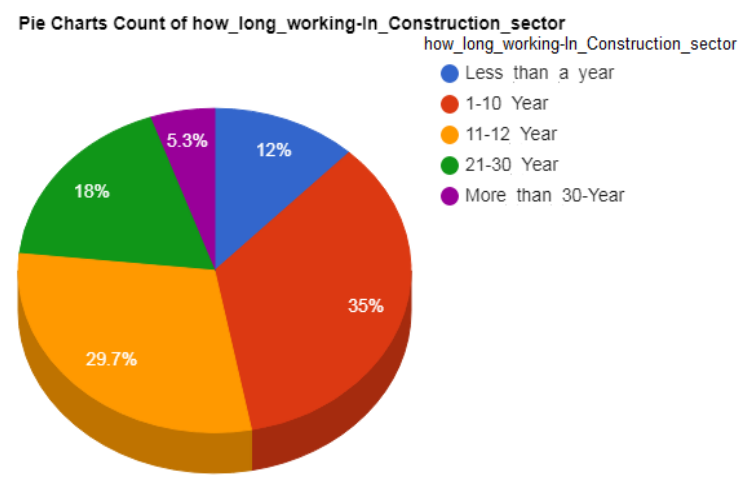

Figure 3. Illustrated working period of workers in the workplace.

Table 2 shown weekly and daily working hours in the form of a cross-tabulation. The Mines Act, 1923 (Section 22-B, C), Factories Act, 1934 (Section-34), 1969 (Section 8), Road Transport Ordinance, 1961(Section-4) and Shops Establishment Ordinance are used to define working hours and break time at different workplaces. Section 34 of the Factories Act described the weekly and daily working hours as follows; from the broad opinion, maximum 48 hours per week is enough. Regular working hours per week with the agreements of the parties is 56 hours, but if the work is seasonal 50 hours per week working time. According to the law no labor is allowed to work more than 9 hours per day (in case of the season; 10 hours). According to table 2, the majority of the labor involved more than 48 hour's limitations of the Factories Act. 
Table 2. Weekly and daily working schedule of employees.

\begin{tabular}{|c|c|c|c|c|c|c|c|c|}
\hline Days & \multicolumn{6}{|c|}{ The average number of hours/per day } \\
\hline per week & $\mathbf{6} \mathbf{h}$ & $\mathbf{7} \mathbf{h}$ & $\mathbf{8} \mathbf{h}$ & $\mathbf{9} \mathbf{h}$ & $\mathbf{1 0} \mathbf{h}$ & $\mathbf{1 1} \mathbf{h}$ & $\mathbf{1 2} \mathbf{~ h}$ \\
\hline $\mathbf{5}$ days & 0 & 0 & 16 & 0 & 0 & 0 & 0 \\
\hline $\mathbf{6}$ days & 11 & 48 & 65 & 32 & 16 & 15 & 0 \\
\hline $\mathbf{7 d a y s}$ & 0 & 0 & 17 & 49 & 15 & 0 & 16 \\
\hline
\end{tabular}

Figure 5 illustrates the job satisfaction level of the staff involved in the survey. As shown in, $10.7 \%$ are unsatisfied with their professions, $21.3 \%$ are neutral, and $68.0 \%$ of the employees are satisfied with their works.

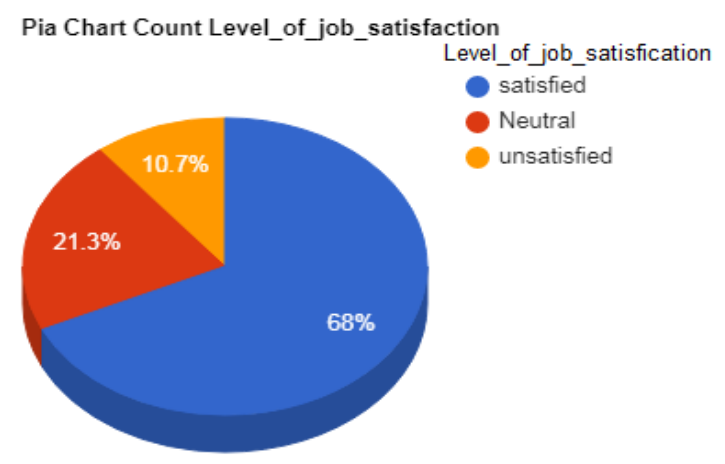

Figure 5 Distribution of workers according to their job satisfaction level.

Figure 6 calculation shows the data of construction workers that they have work experience to another company before joining the construction side. Accordingly, $37.0 \%$ of the workers have knowledge working in a different business sector while the $63.0 \%$ majority of the worker did not have working experience before working in the construction company. Few of the companies have programmed as fishing, beekeeping, the barbers, shoemaking, municipal workers, picking tea leaves, shepherding, café house/tea shop management, and warehouse workforces, etc. 


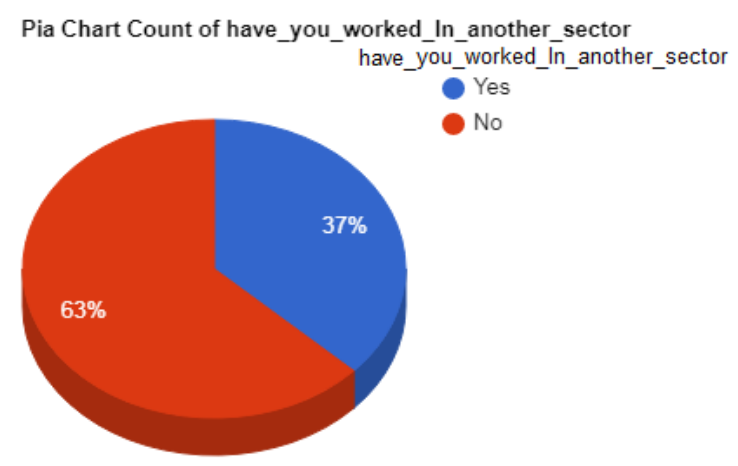

Figure 6. Dispersal of the workers have works experience of different sectors before joining the construction side.

Figure 7 illustrates whether construction workers read books that are involved in the survey. As shown in the results, it observed that $66.0 \%$ of the construction staff not habitual of reading books, although 34.0\% used to. It has been examining that 102 workers are readers, $43.3 \%$ read religious books, $17.7 \%$ read historic books, 33.0\% read stories, and $6.0 \%$ read all categories of books. Also; this frequency distribution shows that the majority of workers who are working in construction companies are uneducated; that way, they are not interested in reading books.

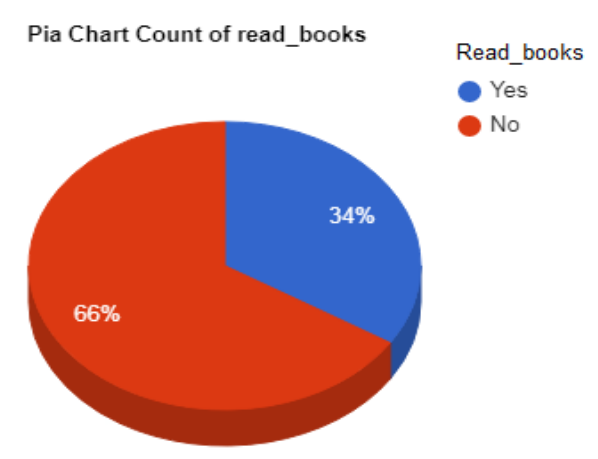

Figure 7. Distribution of workers according to whether they involve in reading books. 


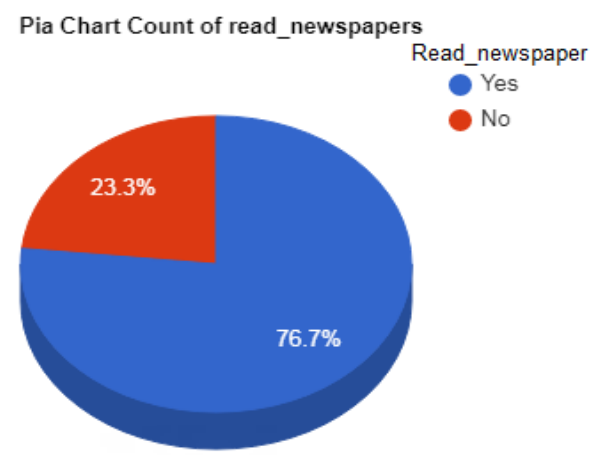

Figure 8. Disruption of construction workers about reading newspapers.

Figure 8 distribution shown that the construction workers read the newspaper or not. As obtained data described that $76.7 \%$ of the staff habitual of reading the newspaper, while $23.3 \%$ of some staff do not like to read the newspaper. It has been declared that the majority of the respondents regular reading the newspaper, $21.3 \%$ read headlines, $22.7 \%$ read all the parts of the newspaper, $6.0 \%$ read magazine portion, $12.0 \%$ read columns, and $38.0 \%$ read the sports news.

Figure 9 described that whether the construction workers watch television. Accordingly, it has been seen that $84.3 \%$ of construction workers like to watch TV, while $15.7 \%$ of construction workers do not like it. It has been declared that the majority of the workers watching TV, 11.7\% watch spiritual, $10.7 \%$ movies, $33.0 \%$ all kind of program, and $33.0 \%$ watch news and $11.6 \%$ watch comedy program.

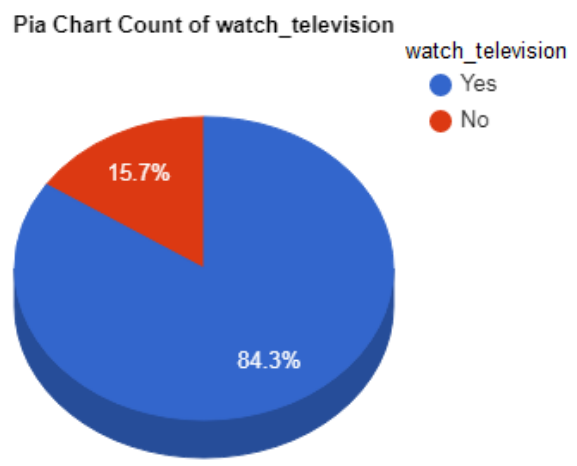

Figure 9. Description of construction workers about watching television. 
Figure 10 shown the data about construction workers who are part of the survey whether they use the internet or not. Accordingly, it has been analyses that $21.7 \%$ of the construction workers use the internet, whereas $78.3 \%$ do not use it. It is also observed that $6.0 \%$ of staff use the internet for shopping purposes, $11.7 \%$ for religious work, $16.0 \%$ use for the current fair, $11.3 \%$ for the sake of research, $20.7 \%$ for watching movies, playing games and $34.3 \%$ use the internet for Facebook, twitter, Instagram.

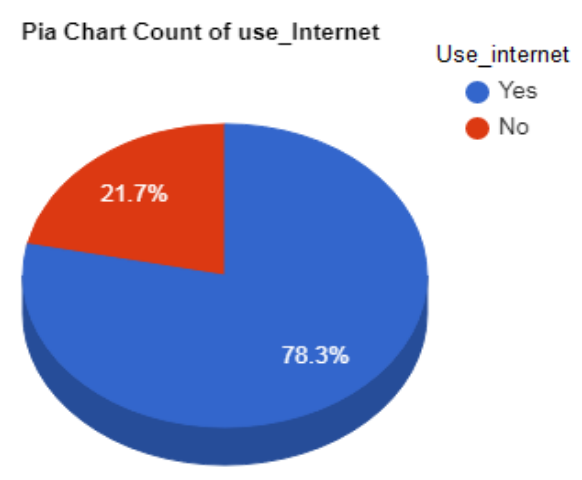

Figure 10. Construction workers according to their use of the internet.

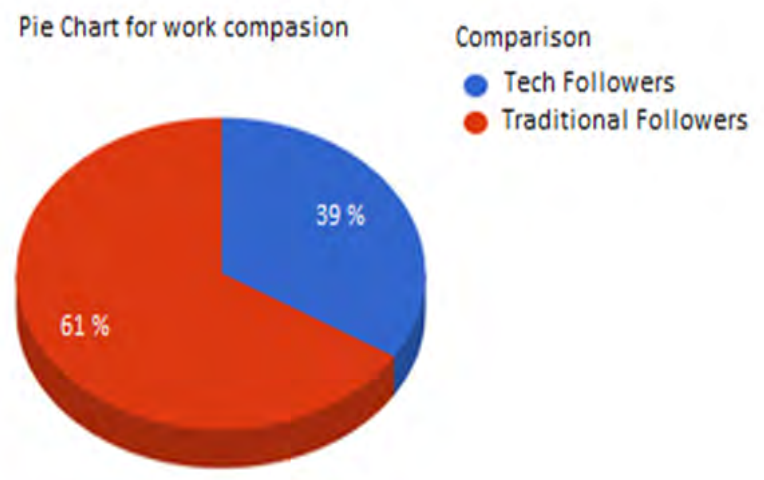

Figure 11. Distribution of workers according to their work method.

Figure 11 described construction workers whether they follow the industrial changes related to the innovations at the construction site (materials, construction tools, and so on). Accordingly, $39.0 \%$ seek the progresses related to the improvements at the 
construction site; perhaps $61.0 \%$ construction workers do not follow the innovations developments. Consequently, 117 workers that fallow the innovations developments, $11.7 \%$ follow the current events over magazines, $10.7 \%$ from goods export construction firms, $44.0 \%$ from the internet, 11.7 from the engineer coworkers and $22.0 \%$ from the construction firms.

Dissemination of the construction workers have knowledgeable any work-related coincidence has been shown in Figure 12. According to this, it has been observed that $16.7 \%$ of the workers suffering from occupational accidents while $83.3 \%$ other workers had never been experienced. 49.3\% experienced work-related accidents once, $22.7 \%$ experienced occupational accidents twice, $10.7 \%$ experienced the occupational accident three times, 5.7\% experienced occupational accidents four times, and $11.6 \%$ experienced occupational accidents five times.

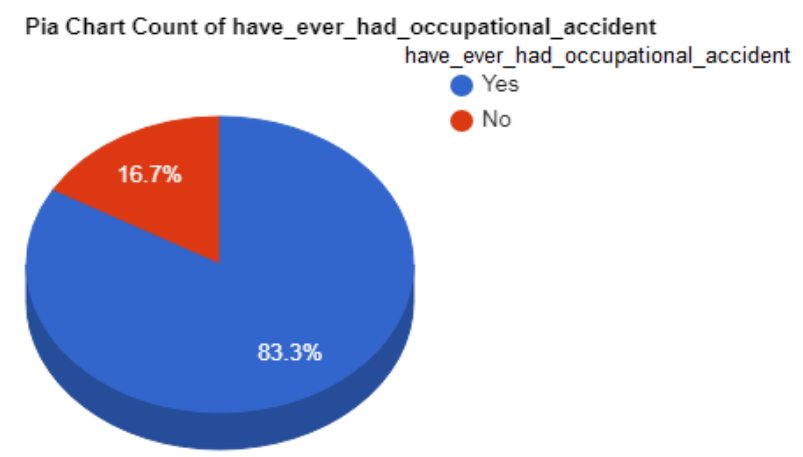

Figure 12. Distribution of whether workers have had occupational accidents.

Dissemination of the work related to OH\&S for the construction workers at the initial stages. As respects the Work-related OH\&S, following law exists in Pakistan: Factories Act 1934. The OH\&S laws in Pakistan generally cover the official zone construction companies. The Factories Act, 1934, the main law covering OH\&S supplies is appropriate to industrial initiatives paying 10 or more labors. Additionally, the Mines Act of 1932 covers the mining zones. Another region is either not enclosed under the $\mathrm{OH} \& \mathrm{~S}$ or the attention is very inadequate, while in Provincial Factories Rules (Sindh Factories Rule 1975) prepared the rules and regulation to the employment law which is practically related to each other. They provide detailed 
rules for the company's inspections, employer certification, and employer's training, working hours, notification and investigation of $\mathrm{OH} \& \mathrm{~S}$ exposures, coincidences, and salaried holidays and so on. In this for the OH\&S training of construction workers, there is the following expression; "the employer must provide the OH\&S training for the construction workers. Practically trained the workers, before starting work, when the job workplace changes, in case of new technology implementation or work equipment changes. Hence, it has been analyzed that $67.0 \%$ of the construction workers receive training on $\mathrm{OH} \& \mathrm{~S}$, whereas $33.0 \%$ did not. The percentage of untrained construction workers and those who have not yet been trained in OH\&S is notable. All 201 trained construction workers listed that they were trained by OH\&S experts.

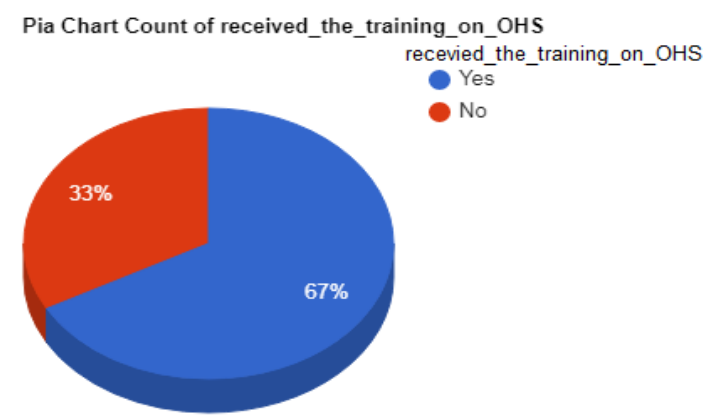

Figure 13. Construction workers training on $\mathrm{OH} \& \mathrm{~S}$.

Figure 14 has been shown the most recent training on the OH\&S. When the most recent training on $\mathrm{OH} \& \mathrm{~S}$ are examined, results described that 201 trainers, 32.7\% received training on the $\mathrm{OH} \& \mathrm{~S}$ in less than one month, $21.3 \%$ in $1-2$ months, $17.7 \%$ in $3-4$ months, $10.7 \%$ in $4-5$ months, $11.7 \%$ in $5-6$ months and $6.0 \%$ since one year. In Factories Act 1934 and Dock Labourers Act 1934 by-law of workers about the Principles and Processes of OH\&S Training, the following expression for this; "the training on OH\&S should be given to the employees working in very hazardous construction companies by the employer at least once a year." According to the survey research, it is observed that $6.0 \%$ of the construction workers were trained on OH\&S more than 14 months and it is analyzed that regulation is not practiced according to the specific schedule. 


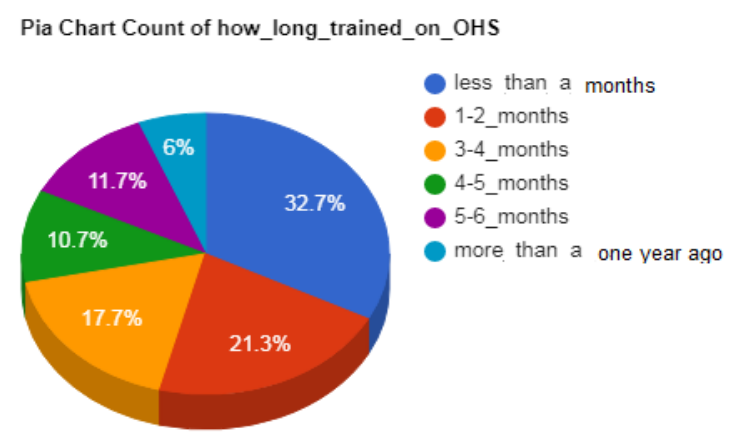

Figure 14. Distribution of workers according to most recent training on $\mathrm{OH} \& \mathrm{~S}$ they receive.

Figure 15 has been shown how the construction workers received the OH\&S related training have assessed the latest training. According to the survey obtained data, of the 201 trainers of OH\&S training, 16.7\% assessed the training as very good, 38.8\% assessed the training is good, $27.3 \%$ assessed the training is intermediate, $12.0 \%$ assessed the training is poor and $6.0 \%$ assessed the training is very poor.

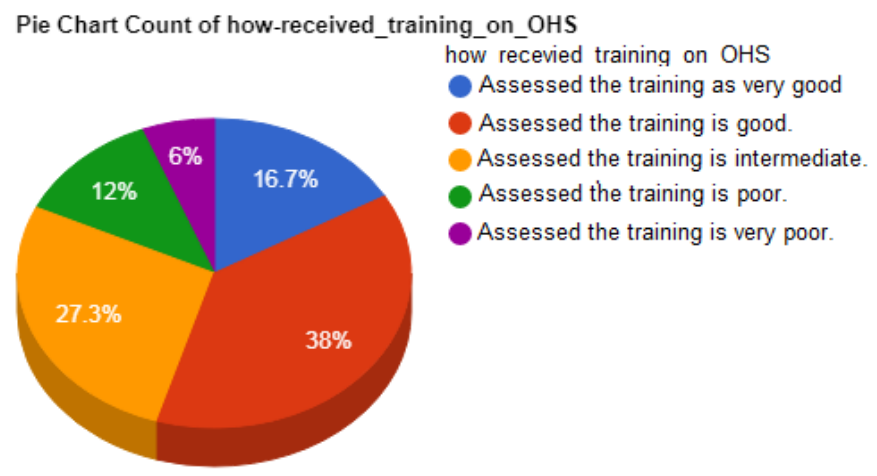

Figure 15. Illustrated the trainer assessment against the $\mathrm{OH} \& S$ related training.

Dissemination of whether the workers' idea about how the most recent training on OH\&S training should has been shown in Figure 16. According to the survey obtained data, $66.7 \%$ of the workers request to receive OH\&S training practically, $10.7 \%$ OH\&S training should be audio base and 22.7\% OH\&S training should be pictorial. Workers statements about the ideas of training content that, while surveys were being done are as follows; "must be taught the occupational hazards types and 
causes of these", "post-accident pictures of those who have a work accident should be exhibited", "must be given the regular and continuous training to the workers on the occupational health and safety", "the training on the occupational health and safety should be explained by shooting short film".

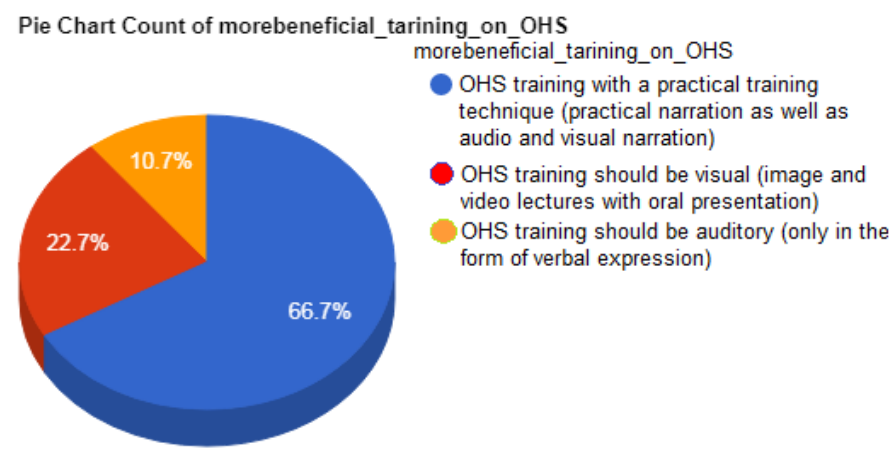

Figure 16. Construction workers' ideas about how OH\&S training.

Distribution of whether the consciousness of employees' tasks for the OH\&S has been shown in Figure 17. According to the survey obtained data, 16.7\% of the workers demanded to be aware of their responsibilities for the OH\&S, while $33.3 \%$ have chosen somewhat aware, and 50.0\% unaware possibilities. Of the 196 participants demanding to have a moral and reasonable level of information, $10.0 \%$ stated they learned their responsibilities from their friends, $45.2 \%$ learned their responsibilities from their $\mathrm{OH} \& \mathrm{~S}$ training, $16.6 \%$ learned their responsibilities from the internet, and $28.2 \%$ learned their responsibilities from their experiences.

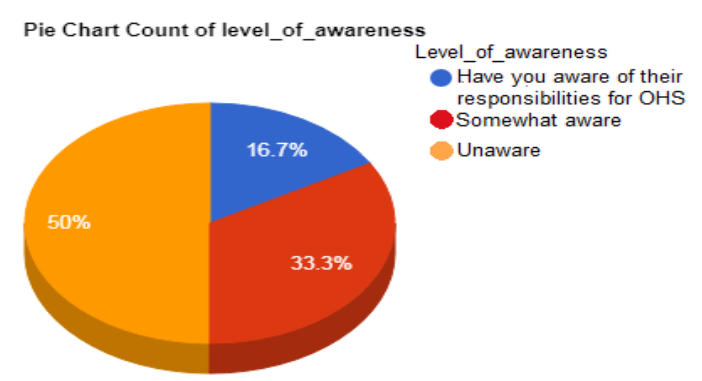

Figure 17. Level of consciousness of construction workers' responsibilities for $\mathrm{OH} \& \mathrm{~S}$. 
To define the connection between the binary variables from the survey, resultant the data Chi-square and Cross-tabulations were used and the important association between two variables is resolute. The obtained data given below that cannot be useful to the Chi-square tests are deduced only in the form of cross tables, while the appropriate chi-square data is presumed by execution Chi-square tests and cross tabulation.

Table 4 shows the association between the construction worker's age group and their satisfaction level. The Chi-square test results with respect to the age group of staff and the level of work gratification have not exposed an important relation $\left(p=0.313^{>0.05}\right)$. It has been analyzing that most of the workers in age groups are dissatisfied with job. The worker's ages go from 30-34 to the age group of over 50 are those who are un-satisfied. While the age group of 18-24 to 25-29, are those who are satisfied with their work. Nevertheless, the quantity of staff who are contented with their jobs, decreases related to the earlier group.

Table 4. The association between the age groups of the construction workers and their satisfaction level.

\begin{tabular}{|c|c|c|c|}
\hline & \multicolumn{3}{|c|}{ Satisfaction level } \\
\hline $\mathbf{A g e}$ & Satisfied & Neutral & Dissatisfied \\
\hline $\mathbf{1 8 - 2 4}$ & 66.250 & 18.750 & 15.000 \\
\hline $\mathbf{2 5 - 2 9}$ & 60.000 & 18.824 & 21.176 \\
\hline $\mathbf{3 0 - 3 4}$ & 58.974 & 30.769 & 10.256 \\
\hline $\mathbf{3 5 - 3 9}$ & 70.000 & 25.000 & 5.000 \\
\hline $\mathbf{4 0 - 4 4}$ & 66.667 & 33.333 & 0.000 \\
\hline $\mathbf{4 5 - 4 9}$ & 63.636 & 9.091 & 27.273 \\
\hline Over 50 & 58.824 & 23.529 & 17.647 \\
\hline Total & $\mathbf{2 0 4}$ & $\mathbf{6 4}$ & $\mathbf{3 2}$ \\
\hline
\end{tabular}

The relation between the construction worker's awareness level and the age group about OH\&S responsibility has shown in Table 6. The Chi-square test results in age groups of workers and the awareness level about OH\&S responsibility have not comprised a substantial relation $(\mathrm{p}=0.622>0.05)$. 
Table 6. Level of responsibilities for OH\&S?

\begin{tabular}{|c|c|c|c|}
\hline Age group & Below average & Average & Above average \\
\hline $\mathbf{1 8 - 2 4}$ & 54.000 & 32.000 & 14.000 \\
\hline $\mathbf{2 5 - 2 9}$ & 41.333 & 36.000 & 22.667 \\
\hline $\mathbf{3 0 - 3 4}$ & 56.410 & 30.769 & 12.821 \\
\hline $\mathbf{3 5 - 3 9}$ & 47.500 & 37.500 & 15.000 \\
\hline $\mathbf{4 0 - 4 4}$ & 66.667 & 16.667 & 16.667 \\
\hline $\mathbf{4 5 - 4 9}$ & 27.273 & 45.455 & 27.273 \\
\hline Over 50 & 52.941 & 35.294 & 11.765 \\
\hline Total & $\mathbf{1 5 0}$ & $\mathbf{1 0 0}$ & $\mathbf{5 0}$ \\
\hline
\end{tabular}

Table 7 has shown the relation between adoptions and the construction worker's age groups. The Chi-square test outcomes to the age group of workers and their approvals of following the technological development/innovations (materials, construction machinery, civil technology etc.) have not comprised a substantial relation $(\mathrm{p}=0.152$ $>0.05)$.

Table 7. The relation between adoptions and construction worker's age group.

\begin{tabular}{|c|c|c|}
\hline Age group & Yes & No \\
\hline $\mathbf{1 8 - 2 4}$ & 38.000 & 62.000 \\
\hline $\mathbf{2 5 - 2 9}$ & 33.333 & 66.667 \\
\hline $\mathbf{3 0 - 3 4}$ & 41.026 & 58.974 \\
\hline $\mathbf{3 5 - 3 9}$ & 50.000 & 50.000 \\
\hline $\mathbf{4 0 - 4 4}$ & 55.556 & 44.444 \\
\hline $\mathbf{4 5 - 4 9}$ & 9.091 & 90.909 \\
\hline Over 50 & 41.176 & 58.824 \\
\hline Total & $\mathbf{1 1 7}$ & $\mathbf{1 8 3}$ \\
\hline
\end{tabular}

Table 8 has shown the relationship between construction workers age groups and their books reading habit. The Chi-square test results with respect to construction workers age groups and their, books reading habit has not comprised a substantial relation $\left(\mathrm{p}=0.817^{>} 0.05\right)$. 
Table 8. The relation between the construction workers age groups and their books reading habit.

\begin{tabular}{|c|c|c|}
\hline & \multicolumn{2}{|c|}{ Books reading? } \\
\hline Age group & Yes & No \\
\hline $\mathbf{1 8 - 2 4}$ & 35.000 & 65.000 \\
\hline $\mathbf{2 5 - 2 9}$ & 38.667 & 61.333 \\
\hline $\mathbf{3 0 - 3 4}$ & 35.897 & 64.103 \\
\hline $\mathbf{3 5 - 3 9}$ & 27.500 & 72.500 \\
\hline $\mathbf{4 0 - 4 4}$ & 22.222 & 77.778 \\
\hline $\mathbf{4 5 - 4 9}$ & 27.273 & 72.727 \\
\hline Over 50 & 35.294 & 64.706 \\
\hline Total & $\mathbf{1 0 2}$ & 198 \\
\hline
\end{tabular}

Table 9 has shown the relation between construction workers age groups and their newspapers reading habit. The Chi-square test results with respect to the construction workers age groups and their newspapers reading habit has not comprised a substantial relation $\left(\mathrm{p}=0.767^{>} 0.05\right)$.

Table 9. The relationship of construction workers between age groups and their newspapers reading habit.

\begin{tabular}{|c|c|c|}
\hline & \multicolumn{2}{|c|}{ Newspapers reading? } \\
\hline Age group & Yes & No \\
\hline $\mathbf{1 8 - 2 4}$ & 78.000 & 22.000 \\
\hline $\mathbf{2 5 - 2 9}$ & 70.667 & 29.333 \\
\hline $\mathbf{3 0 - 3 4}$ & 79.487 & 20.513 \\
\hline $\mathbf{3 5 - 3 9}$ & 77.500 & 22.500 \\
\hline $\mathbf{4 0 - 4 4}$ & 88.889 & 11.111 \\
\hline $\mathbf{4 5 - 4 9}$ & 81.818 & 18.182 \\
\hline Over 50 & 70.588 & 29.412 \\
\hline Total & $\mathbf{2 3 0}$ & $\mathbf{7 0}$ \\
\hline
\end{tabular}

Table 10 has shown the relation between the educational ability of the workers and their books reading habit. The Chi-square test results with respect to the construction workers level of education and their, books reading habit has not comprised a substantial relation $\left(p=0.384^{>} 0.05\right)$. 
Table 10. The relation between the educational ability of the workers and their books reading habit.

\begin{tabular}{|c|c|c|}
\hline & \multicolumn{2}{|c|}{ Books reading? } \\
\hline Level of Education & Yes & No \\
\hline Grad 5 & 35.878 & 64.122 \\
\hline Grad 8 & 34.211 & 65.789 \\
\hline Grad 10 & 38.889 & 61.111 \\
\hline Diploma & 23.810 & 76.190 \\
\hline Bachelor's Degree & 16.667 & 83.333 \\
\hline Total & 102 & 198 \\
\hline
\end{tabular}

Table 14 has shown the relation between the educational ability of the workers and work-related accident rate. The Chi-square test results with respect to the level of education and work-related accident rate have not comprised a substantial relation $(\mathrm{p}$ $\left.=0.940^{>} 0.05\right)$. Moreover, according to the percentage given in the tables, the highest rate of having a work-related accident belongs to the Grad 5 school graduate with 24 , while the lowest rate is those with a bachelor's degree with 2.

Table 14. The relation between the educational ability of the workers and occupational accident rate of the workers.

\begin{tabular}{|c|c|c|}
\hline Level of Education & Have you ever had an occupational accident? \\
\hline Grad 5 & Yes & No \\
\hline Grad 8 & 18.321 & 81.679 \\
\hline Grad 10 & 15.789 & 84.211 \\
\hline Diploma & 16.667 & 83.333 \\
\hline Bachelor's Degree & 14.286 & 85.714 \\
\hline Total & 11.111 & 88.889 \\
\hline
\end{tabular}

Table 15 has shown the relation between the status of work-related accidents and the awareness level of responsibilities for the OH\&S. The Chi-square test results with respect to the level of awareness of workers duties for the OH\&S and the status of work-related accidents has comprised a substantial relation. $\left(p=0.001^{<} 0.05\right)$. 
Table 15. The relation between the awareness level of workers responsibilities for work-related health and safety.

\begin{tabular}{|c|c|c|}
\hline $\begin{array}{c}\text { The level } \\
\text { responsibilities for } \\
\text { OH\&S? }\end{array}$ & \multicolumn{2}{|c|}{ Have you ever had occupational accidents? } \\
\hline Above average & Yes & No \\
\hline Average & 0.000 & 100.000 \\
\hline Below average & 15.000 & 85.000 \\
\hline Total & 23.333 & 76.667 \\
\hline
\end{tabular}

Table 16 has shown the relation between the awareness ability of the workers and their working hours in the construction sector about OH\&S responsibilities. The Chi-square test results with respect to the awareness ability of the workers and their working hours in the construction sector about OH\&S responsibilities has not comprised a substantial relation. $\left(\mathrm{p}=0.887^{>} 0.05\right)$.

Table 16. The relation between the construction workers awareness level about OH\&S responsibilities and their working duration in the construction sector.

\begin{tabular}{|c|c|c|c|}
\hline & \multicolumn{3}{|c|}{ Level of responsibilities for OH\&S? } \\
\hline Duration & Above average & Average & Below average \\
\hline Less than a year & 8.333 & 38.889 & 52.778 \\
\hline $\mathbf{1 - 1 0}$ years & 16.190 & 30.476 & 53.333 \\
\hline $\mathbf{1 1 - 2 0}$ years & 20.225 & 32.584 & 47.191 \\
\hline $\mathbf{2 1 - 3 0}$ years & 16.667 & 37.037 & 46.296 \\
\hline Over 30 years & 18.750 & 31.250 & 50.000 \\
\hline Total & 50 & 100 & 150 \\
\hline
\end{tabular}

\section{DISCUSSIONS}

The comparison of the data found in a survey according to the Law in Pakistan. The current OH\&S training programs for the construction companies are not appropriately practices in Pakistan. Most of the recent research addressed only on safety issues irrespective of present health risks in the construction companies (Yiu, Sze, \& Chan, 2018). 
It was analyzed that $20.0 \%$ of the employees in the construction industry are not entitled to the relevant skilled certificate. The Technical Education Commission focus and National Vocational to grow work-related, skills values, programs, and employment testing certificate system for all sectors in which technical education and vocational training are conveyed. These trainings facilitate the professional education and vocational training to meet national and international demand for skilled workforce (Arthur-Mensah \& Alagaraja, 2018). Workers do not possess the relevant qualified certificate would not be able to work in the construction industry. Additionally, the workers do not have the proficiency certificate will not allow attaining any training and comprehensive particulars of his work.

Conferring to the survey information, $32.3 \%$ of the personnel were labor seven days. A large proportion of workers indicated that they work without any taking a day off and they absent from their duty only for specific reasons like sickness, heavy rain or to attend the funeral of close relatives. Hence, they are deprived of their rights provided by the Factories Act, 1934 (Section-34). Also, most of the workers (81\%) have been observed to work more than the maximum 56 hours limitations in the Shops and Establishments Ordinance 1969 and Mines Act 1923. The employee's health is affected, they are seen tedious, tired, an unmotivated, by the result of the workload and irregular sleep schedule. As an outcome of this circumstance emotional disturbances such as the inability to concentrate, training disparate attitudes that may happen through work become a threat to OH\&S of the employees.

According to the survey obtained data, it is perceived that $61.0 \%$ of the employees intricate the research are not attentive to bring the industrial development/ innovations related to the construction industry, $66.0 \%$ cannot read books; similarly $23.3 \%$ are not usually read newspapers, and $78.3 \%$ do not browse the internet. The factors above directed that training must be given to the employees under the Dock Labourers, Factories Act 1934. Those workers are essential for the industries which have habits of reading books or newspapers and take research into sympathy.

Furthermore, $84.3 \%$ of the employees engaged in the research survey that they watch television. It is examined that use the TV would be playing a significant role 
in determining the importance of $\mathrm{OH} \& \mathrm{~S}$ issues. Additionally, public opinion can be raised by fixing the advertisement billboard on "Public Spot".

$16.7 \%$ of the workers are reported to have occupational accidents, while $83.3 \%$ are not. It has been noted that among the primary school graduates with $43.7 \%$, the proportion of crashes amongst workers is considerably high.

$33.0 \%$ of the employees concerned with the survey quantified that they have not received training on OH\&S. Partially the employers have not satisfied their responsibilities to deliver workers training, stated in Provincial Factories Rules.

It is examined that $35.0 \%$ of the employees were accomplished the OH\&S training past year, which shows that they get an education of OH\&S at least once a year, so the directive on actions and codes of $\mathrm{OH} \& \mathrm{~S}$ training programs, has been desecrated.

The study has also been observed the rate of internet usage among different age groups and found inverse proportional between them. Likewise, the reading rate of the employees increases as the education level of the employee's increases. On the other hand, it has been examined that the price of internet use increases as the education level of the employees increases too.

Irrespectively the level of education of the employees and their age distribution, the overwhelming immense number of workers desire effective OH\&S training practices. Hence, according to the age and educational background of the workers, this demand did not differ.

According to the survey obtained data, $38.44 \%$ of the construction workers related to the study stated that they are under conscious of their duties connected to the OH\&S. According to the National Action Plan for Health Promotion in Pakistan; the worker's training program can be measured as a leading practice by which the present state of the construction company concerning the OH\&S standpoint, the construction companies can be categorized as precarious companies. Therefore, it is essential to approve a regular monitoring program to develop its condition in terms of OH\&S considerations. There must be workers are to be educated about the 
features of the OH\&S. The data of this survey clarified that OH\&S scheme had not been implemented according to its standard as per law.

\section{CONCLUSION AND SUGGESTION}

Ensure that for doing OH\&S education training that is compulsory to employees bestowing to Control and Health Promotion, the National Action Plan for Prevention in Pakistan, more pacifists; it is compulsory to have exact workers profile information who will receive $\mathrm{OH} \& \mathrm{~S}$ training. In this research, one-to-one interviews and questionnaires were directed with employees to find out the general opinion of workers and their general views on OH\&S in Pakistan. To find out the result for frequency analysis, cross-tabulation and Chi-square tests have been applied.

- According to Control and Health Promotion, the National Action Plan for Prevention in Pakistan, the planned significant change in OH\&S has not been wholly recognized in Pakistan.

- The worker's training which is the utmost essential foundation of info on $\mathrm{OH} \& \mathrm{~S}$ has not been accompanied efficiently and appropriately.

The data obtained from this research are beneficial following the recommendations are assumed to make the OH\&S training more accurate and useful. Whereas the worker's experience, education level, and their ages are quite diverse, it's compulsory when a group of workers was trained, and the education level is being formed must be these factors under consideration.

\section{REFERENCES}

Akhter, M. N., \& Deputy, R. (2011). A Comparative Study on Vocational Training Structure of Pakistan with British and German Model. International Journal of Business and Social Science, 2(1), 162-169. 
Arditi, D., \& Mochtar, K. (2000). Trends in productivity improvement in the US construction industry. Construction Management and Economics, 18(1), 15-27. doi: https://doi.org/10.1080/014461900370915

Arthur-Mensah, N., \& Alagaraja, M. (2018). Examining training and skills development of youth and young adults in the Ghanaian context: an HRD perspective. Human Resource Development International, 21(5), 493-508. doi: https:// doi.org/10.1080/13678868.2018.1468587

Awwad, R., El Souki, O., \& Jabbour, M. (2016). Construction safety practices and challenges in a Middle Eastern developing country. Safety Science, 83, 1-11. doi: https://doi.org/10.1016/J.SSCI.2015.10.016

By, P., Mushtaq, F., \& Khalid, M. (2015). Occupational Injuries in Pakistan: Incidences and Economic Impac, 72. Retrieved from: http://www.pide.org.pk/ pdf/HealthEconomics/Thesis_Faisal.pdf

Gheng, G.-W., Leu, S.-S., Gheng, Y.-M., Wu, T.-G., \& Lin, G.-G. (2012). Applying data mining techniques to explore factors contributing to occupational injuries in Taiwan's construction industry. Accident Analysis \& Prevention, 48, 214222. doi: https://doi.org/10.1016/J.AAP.2011.04.014

Friend, M. A., \& Kohn, J. P. (n.d.). Fundamentals of occupational safety and health.

Huang, X., \& Hinze, J. (2006). Owner's Role in Construction Safety: Guidance Model. Fournal of Construction Engineering and Management, 132(2), 174-181. doi: https://doi.org/10.1061/(ASCE)0733-9364(2006)132:2(174)

Hussain, J., Shabbir, F., Shamim, M. A., Naeem, U., Ejaz, N., Naeem, U. A., ... Farooq, Q. U. (2013). Assessment of most critical success factors for mega construction projects in Pakistan Carcinogenicity of pesticides in humans View project Effect of Addition of Nanomaterials on Engineering Properties of Asphalt Binder View project Assessment of most critical success factors for mega construction projects in Pakistan. Life Science Fournal, 10. Retrieved from: http:// www.lifesciencesite.comhttp//www.lifesciencesite.com.41 
Imriyas, K., Pheng, L. S., \& Teo, E. A. (2007). A framework for computing workers' compensation insurance premiums in construction. Construction Management and Economics, 25(6), 563-584. doi: https://doi.org/10.1080/01446190601110116

Jain, A., Leka, S., \& Zwetsloot, G. I. J. M. (2018). The Economic, Business and Value Case for Health, Safety and Well-Being, 67-98. Springer, Dordrecht. doi: https://doi. org/10.1007/978-94-024-1261-1_3

Jarullah, A. T., Abed, F.M., Ahmed, A.M., \& Mujtaba,I. M. (2019). Optimisation of several industrial and recently developed AJAM naphtha isomerization processes using model based techniques. Computers $\mathbb{E}$ Chemical Engineering, 126, 403-420. doi: https://doi.org/10.1016/J.COMPCHEMENG.2019.04.018

Kazaz, A., \& Acıkara, T. (2015). Comparison of Labor Productivity Perspectives of Project Managers and Craft Workers in Turkish Construction Industry. Procedia ComputerScience, 64,491-496. doi: https://doi.org/10.1016/J.PROCS.2015.08.548

Khan, M. W., Ali, Y., De Felice, F., \& Petrillo, A. (2019). Occupational health and safety in construction industry in Pakistan using modified-SIRA method. Safety Science, 118, 109-118. doi: https://doi.org/10.1016/J.SSCI.2019.05.001

Mahamid, I. (2013). Contractors perspective toward factors affecting labor productivity in building construction. Engineering, Construction and Architectural Management, 20(5), 446-460. doi: https://doi.org/10.1108/ECAM-08-2011-0074

Marcum, J. L., Foley, M., Adams, D., \& Bonauto, D. (2018). Characteristics of construction firms at risk for future workers' compensation claims using administrative data systems, Washington State. Fournal of Safety Research, 65, 5358. doi: https://doi.org/10.1016/J.JSR.2018.02.005

Mazlina Zaira, M., \& Hadikusumo, B. H. W. (2017). Structural equation model of integrated safety intervention practices affecting the safety behaviour of workers in the construction industry. Safety Science, 98, 124-135. doi: https://doi. org/10.1016/J.SSCI.2017.06.007 
Mohamed, S., Ali, T. H., \& Tam, W. Y. V. (2009). National culture and safe work behaviour of construction workers in Pakistan. Safety Science, 47(1), 29-35. doi: https://doi.org/10.1016/J.SSCI.2008.01.003

Mohd Kamar, I. F., Lop, N. S., Mat Salleh, N., Mamter, S., \& Suhaimi, H. A. (2014). Contractor's Awareness on Occupational Safety and Health (OSH) Management Systems in Construction Industry. E3S Web of Conferences, 3, 01019. doi: https://doi.org/10.1051/e3sconf/20140301019

Raheem, A. A., \& Issa, R. R. A. (2016). Safety implementation framework for Pakistani construction industry. Safety Science, 82, 301-314. doi: https://doi. org/10.1016/J.SSCI.2015.09.019

Riaño-Casallas, M. I., \& Tompa, E. (2018). Cost-benefit analysis of investment in occupational health and safety in Colombian companies. American fournal of Industrial Medicine, 61(11), 893-900. doi: https://doi.org/10.1002/ajim.22911

Sámano-ríos, M. L., Ijaz, S., Ruotsalainen, J., Breslin, F. G., Gummesson, K., \& Verbeek,J. (2019). Occupational safety and health interventions to protect young workers from hazardous work-A scoping review. Safety Science, 113, 389403. doi: https://doi.org/10.1016/j.ssci.2018.11.024

Seo, J., Han, S., Lee, S., \& Kim, H. (2015). Computer vision techniques for construction safety and health monitoring. Advanced Engineering Informatics, 29(2), 239-251. doi: https://doi.org/10.1016/J.AEI.2015.02.001

Shin, I., Oh, J.-B., \& Yi, K. H. (2011). Workers' Compensation Insurance and Occupational Injuries. Safety and Health at Work, 2(2), 148-157. doi: https://doi. org/10.5491/SHAW.2011.2.2.148

Singh, A. (1979). The 'Basic Needs' approach to development vs the new international economic order: The significance of Third World industrialization. World Development, 7(6), 585-606. doi: https:/ /doi.org/10.1016/0305-750X(79)90095-0

Sørensen, O. H., Hasle, P., \& Bach, E. (2007). Working in small enterprises-Is there a special risk? Safety Science, 45(10), 1044-1059. doi: https://doi.org/10.1016/J. SSCI.2006.09.005 
Weissbrodt, R., \& Giauque, D. (2017). Labour inspections and the prevention of psychosocial risks at work: A realist synthesis. Safety Science, 100, 110-124. doi: https://doi.org/10.1016/J.SSCI.2017.02.012

Wu, G., Luo, X., Wang, T., Wang, Y., \& Sapkota, B. (2018). Safety challenges and improvement strategies of ethnic minority construction workers: a case study in Hong Kong. International Fournal of Occupational Safety and Ergonomics, 1-11. doi: https://doi.org/10.1080/10803548.2018.1466508

Yiu, N. S. N., Sze, N. N., \& Ghan, D. W. M. (2018). Implementation of safety management systems in Hong Kong construction industry-A safety practitioner's perspective. Fournal of Safety Research, 64, 1-9. doi: https://doi.org/10.1016/J. JSR.2017.12.011

Zaid, A. A., Jaaron, A. A. M., \& Talib Bon, A. (2018). The impact of green human resource management and green supply chain management practices on sustainable performance: An empirical study. Fournal of Cleaner Production, 204, 965-979. doi: https://doi.org/10.1016/JJCLEPRO.2018.09.062 
Edición Especial Special Issue Noviembre 2019

DOI: http://dx.doi.org/10.17993/3ctecno.2019.specialissue3.253-285 